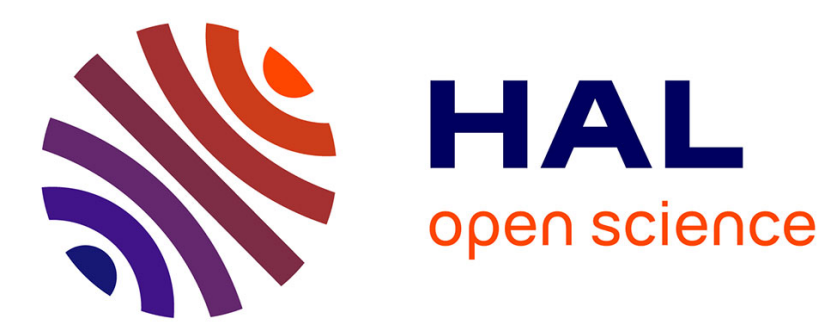

\title{
Excited states of protonated DNA/RNA bases
}

Matias Berdakin, Géraldine Féraud, Claude Dedonder-Lardeux, Christophe Jouvet, Gustavo A. Pino

\section{To cite this version:}

Matias Berdakin, Géraldine Féraud, Claude Dedonder-Lardeux, Christophe Jouvet, Gustavo A. Pino. Excited states of protonated DNA/RNA bases. Physical Chemistry Chemical Physics, 2014, in press. 10.1039/C4CP00742E . hal-00968512

\section{HAL Id: hal-00968512 https://hal.science/hal-00968512}

Submitted on 1 Apr 2014

HAL is a multi-disciplinary open access archive for the deposit and dissemination of scientific research documents, whether they are published or not. The documents may come from teaching and research institutions in France or abroad, or from public or private research centers.
L'archive ouverte pluridisciplinaire HAL, est destinée au dépôt et à la diffusion de documents scientifiques de niveau recherche, publiés ou non, émanant des établissements d'enseignement et de recherche français ou étrangers, des laboratoires publics ou privés. 


\title{
Excited states of protonated DNA/RNA bases
}

\author{
Matias Berdakin ${ }^{1}$, Géraldine Féraud ${ }^{2}$, Claude Dedonder-Lardeux, ${ }^{2}$ Christophe \\ Jouvet $^{2 *}$ and Gustavo A. Pino ${ }^{1 *}$
}

1 INFIQC (CONICET - Universidad Nacional de Córdoba) Dpto. de Fisicoquímica - Facultad de Ciencias Químicas - Centro Láser de Ciencias Moleculares - Universidad Nacional de Córdoba, Ciudad Universitaria, X5000HUA Córdoba, Argentina

${ }^{2}$ CNRS, Aix Marseille Université, Physique des Interactions loniques et Moléculaires (PIIM): UMR7345, 13397 Marseille, France

*Corresponding authors: Christophe.jouvet@univ-amu.fr_gpino@fcq.unc.edu.ar

\section{Abstract}

The very fast relaxation of the excited states to the ground state in DNA/RNA bases is a necessary process to ensure the photostability of DNA and its rate is highly sensitive to the tautomeric form of the bases. Protonation of the bases plays a crucial role in many biochemical and mutagenic processes and it can result in alternative tautomeric structures, thus making important the knowledge of the properties of protonated DNA/RNA bases. We report here the photofragmentation spectra of the five protonated DNA/RNA bases. In most of the cases, the spectra exhibit well resolved vibrational structures, with broad bands associated with very short excited state lifetimes. The similarity between the electronic properties e.g. excitation energy and very short excited state lifetimes for the canonical tautomers of protonated and neutral DNA bases, suggests that the former could also play an important role in the photostability mechanism of DNA. 


\section{Introduction}

Understanding the response of the DNA/RNA bases to UV radiation is critical since their photochemistry constitutes a fundamental step in radiation-induced DNA/RNA damage and very likely it had also played an important role in prebiotic chemistry. ${ }^{1}$ In the recent years, experimental and theoretical groups have been working extensively and settling benchmark results to disentangle the intrinsic properties of these building blocks of life in the gas phase. These studies have been recently reviewed in three complete papers. ${ }^{1-3}$

The neutral DNA bases are structurally rich given that they can exist in many tautomeric forms. However, nature has chosen those structures (the canonical forms) shown in Fig. 1, that allow for a precise recognition between $\mathrm{C}$ (cytosine) and $\mathrm{G}$ (guanine) through three $\mathrm{H}$-bonds and between $\mathrm{T}$ (thymine) or $\mathrm{U}$ (uracil) and $\mathrm{A}$ (adenine) through a double $\mathrm{H}$-bond, to guarantee the preservation of the genetic information encoded in the DNA molecule. The excited state lifetimes of DNA bases depend strongly on their tautomeric form, the canonical tautomers being those with the shortest excited state lifetime, which is considered to be the natural photoprotection mechanism of DNA. ${ }^{1-3}$
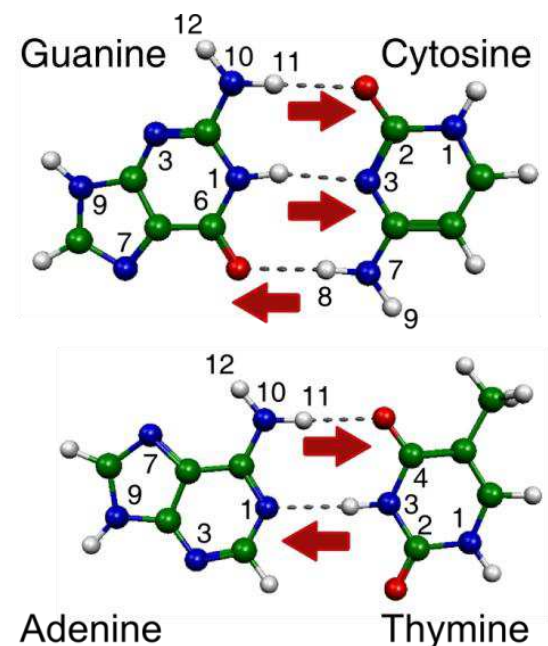

Figure 1. Watson-Crick (WC) structures of the DNA base pairs. The red arrows indicate possible protonation sites of canonical tautomers through a proton transfer reaction within the WC pair. 
DNA bases are susceptible to protonation through proton transfer or other reaction mechanisms. ${ }^{4,5}$ The protonation processes are important because alternative tautomeric structures of the DNA bases can be formed. The existence of such non-canonical tautomers could induce longer excited state lifetimes ${ }^{1-3}$ or development of mutations in the nucleic acid replication because the $\mathrm{H}$ bonding structure changes leading to failures in the recognition process. ${ }^{5-10}$

An excited state proton/hydrogen transfer reaction in the Watson Crick (WC) GC pair, has been identified by Sobolewski and Domcke ${ }^{11}$ as one of the most important deactivation pathways of the photoexcited pair in the gas phase. Therefore, in a bottom-up strategy to build up a whole photochemical and photophysical model of DNA, understanding the structure of protonated DNA bases, their tautomeric forms, stability and the effects of protonation on the excited state lifetime and absorption spectra is of imperative relevance to calibrate the calculations with experimental results. However, very few detailed studies have been done on these protonated bases ${ }^{5-7,12-14}$ as compared with the numerous studies performed on the neutral species. ${ }^{1-3}$

We performed a detailed study of the electronic spectroscopy of the five cold protonated DNA/RNA bases $\left(\mathrm{CH}^{+}, \mathrm{TH}^{+}, \mathrm{UH}^{+}, \mathrm{GH}^{+}\right.$and $\left.\mathrm{AH}^{+}\right)$by means of photofragmentation spectroscopy in a cold ion trap that allows getting information about their excitation energies and excited state lifetimes. Structural assignment is obtained with ab-initio calculations in the ground and excited states.

\section{Methodology}

\section{2.a. Experiment}

The electronic spectra of the protonated aromatic DNA/RNA bases were obtained via parent ion photo-fragment spectroscopy in a cryogenically-cooled quadrupole ion trap (Paul Trap from Jordan TOF Products, Inc.). (15) The setup is similar to the one developed in several groups based on the original design by Wang and Wang. ${ }^{16-18}$ The protonated ions are produced in an electrospray ionization source 
built at Aarhus University. ${ }^{19}$ At the exit of the capillary, ions are trapped in an octopole trap for $90 \mathrm{~ms}$. They are extracted by applying a negative pulse of c.a. $50 \mathrm{~V}$ and are further accelerated to $190 \mathrm{~V}$ by a second pulsed voltage just after the exit electrode. This time sequence of pulsed voltages produces ion packets with duration between 500 ns and $1 \mu \mathrm{s}$. The ions are driven by a couple of electrostatic lenses toward the Paul trap biased at $190 \mathrm{~V}$ so that the ions enter the trap gently avoiding fragmentation induced by collisions. A mass gate placed at the entrance of the trap allows selecting the parent ion. The Paul trap is mounted on the cold head of a cryostat (Coolpak Oerlikon) connected to a water-cooled He compressor. Helium as buffer gas is injected in the trap using a pulsed valve (General Valve) triggered $1 \mathrm{~ms}$ before the ions enter the trap as previously reported by Kamrath et al. ${ }^{18}$ The ions are trapped and thermalized at a temperature between 20 and $50 \mathrm{~K}$ through collisions with the cold buffer gas (see S.I.). The ions are kept in the trap for several tens of ms before the photodissociation laser is triggered. This delay is necessary to ensure thermalization of ions and efficient pumping of the He buffer gas from the trap to avoid collision induced dissociation of the ions during the extraction towards the $1.5 \mathrm{~m}$ long timeof-flight mass spectrometer. After laser excitation, the ions are stored in the trap for a delay that can be varied between 20 and 90 ms before extraction to the TOF mass spectrometer. The complete mass spectrum is recorded on a micro channel plate (MCP) detector with a digitizing storage oscilloscope interfaced to a PC. The photofragment yield spectrum of each detected ion is normalized to the parent ion signal and the laser power.

The photo-dissociation laser is an OPO laser from EKSPLA, which has a $10 \mathrm{~Hz}$ repetition rate, 10 ns pulse width, a resolution of $10 \mathrm{~cm}^{-1}$ and a scanning step of $0.02 \mathrm{~nm}$. The laser is shaped to a $1 \mathrm{~mm}^{2}$ spot to fit the entrance hole of the trap and the laser power is around $20 \mathrm{~mW}$ in the UV spectral region. 


\section{2.b. Calculations}

$A b$ initio calculations have been performed with the TURBOMOLE program package, ${ }^{20}$ making use of the resolution-of-the-identity (RI) approximation for the evaluation of the electron-repulsion integrals. ${ }^{21}$ The equilibrium geometries of the protonated species in their ground states $\left(\mathrm{S}_{0}\right)$ have been determined at the MP2 (Møller-Plesset second order perturbation theory) level. Vertical excitation energies of the lowest excited singlet states have been determined at the RI-ADC(2)(second order Algebraic Diagrammatic Construction) level. ${ }^{22}$ Due to numerous conical intersections between the $\mathrm{n} \pi *$ and $\pi \pi^{*}$ states, the excited state optimization is not straightforward and failed in many systems as shown already for protonated adenine. ${ }^{12,13}$ Calculations were performed with the correlation-consistent polarized valence double-zeta (cc-pVDZ or aug-cc-pVDZ) basis set. ${ }^{23}$ The vibrations in the ground and excited states have been calculated for the enol/1H-2 $\mathrm{H}^{24}$ tautomer of protonated cytosine and the electronic spectra simulated using the Pgopher software ${ }^{25}$ for Franck Condon analysis.

\section{Results}

The spectra of all the cold protonated DNA/RNA bases are presented in Fig. 2. The laser has been scanned at lower energy up to $410 \mathrm{~nm}$ but no signal was detected below the bands shown here.

For all the protonated molecules, the fragments observed in these experiments are the same as those observed in collision induced dissociation (CID) or in infrared multi-photon dissociation (IRMPD): $\mathrm{NH}_{3}$ loss, $\mathrm{H}_{2} \mathrm{O}$ loss and $\mathrm{HNCO} / \mathrm{H}_{2} \mathrm{NCN}$ loss, which means that very likely these fragments come from dissociation in the ground state following internal conversion (IC). Internal conversion following UV excitation (e.g. $310 \mathrm{~nm}$ ) leads to the production of ions in the $S_{0}$ state with $4 \mathrm{eV}\left(32000 \mathrm{~cm}^{-1}\right)$ of vibrational excitation, which is above the dissociation threshold of all the systems studied in this work. This allows us to neglect the possibility of missing of some transition due to low dissociation yield. 
Most of the bands are very broad except those of $\mathrm{GH}^{+}$in the low energy region of the spectrum for which the width of the vibrational bands is limited by the laser bandwidth and the rotational contour $\left(12 \mathrm{~cm}^{-1}\right)$ and the low energy band system of $\mathrm{UH}^{+}$, which has only slightly broader bandwidths $\left(19 \mathrm{~cm}^{-1}\right)$.

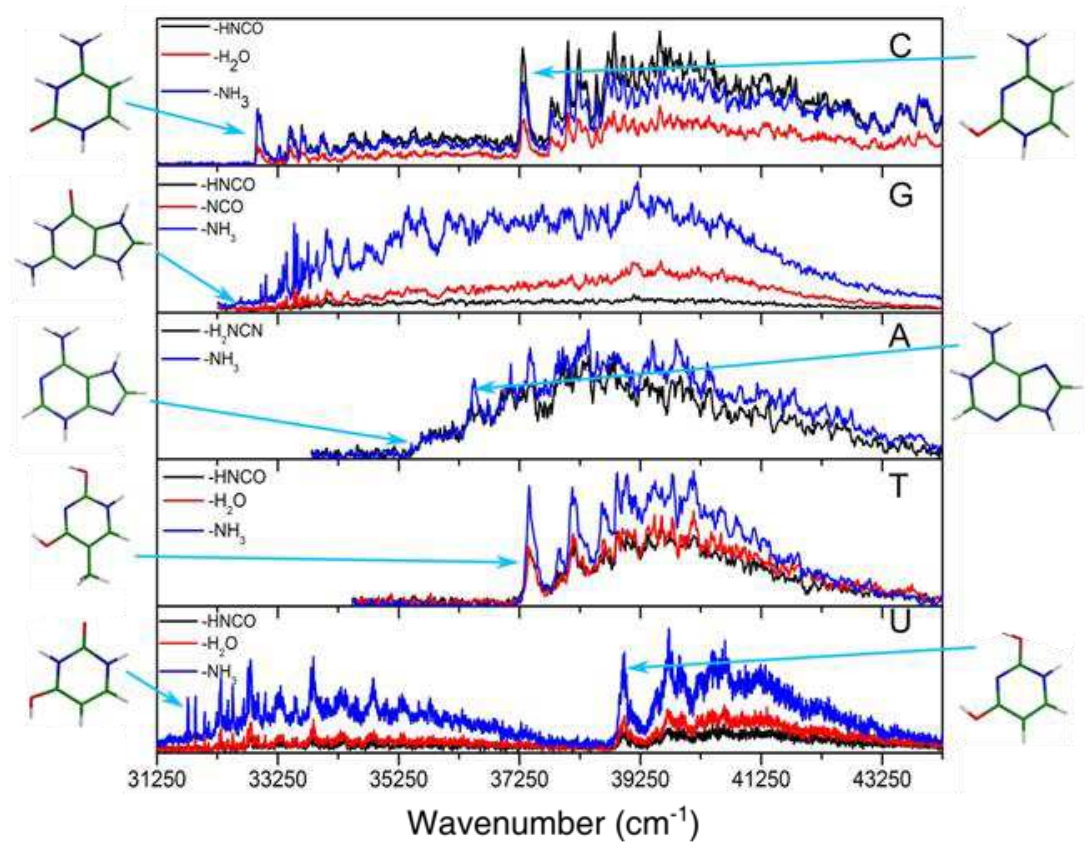

Figure 2. Electronic photofragmentation spectra of the cold protonated DNA/RNA bases recorded on different fragmentation channels: $\mathrm{HNCO}$ or $\mathrm{H}_{2} \mathrm{NCN}$ loss in black, $\mathrm{H}_{2} \mathrm{O}$ or $\mathrm{NCO}$ loss in red and $\mathrm{NH}_{3}$ loss in blue. Protonated cytosine (upper panel) and protonated uracil (lowest panel) present clearly two band systems, while thymine and guanine present only one. All the electronic transitions can be assigned to the lowest energy ground state tautomers.

In the case of the protonated pyrimidine bases, for $\mathrm{CH}^{+}$and $\mathrm{UH}^{+}$clearly two band systems (hereafter called the blue and red systems according to their absorption region) are observed, which might be due to two electronic states or two isomers. However, only one system is observed for $\mathrm{TH}^{+}$in the $(34250-44250) \mathrm{cm}^{-1}$ spectral range, while the low resolution spectra in the $(33330-30300) \mathrm{cm}^{-1}$ spectral region did not show any transition associated to $\mathrm{TH}^{+}$(see S. I.) An enlarged view of the spectra near the band origins for the protonated pyrimidine bases is shown in Fig. 3 . The broad character of the 
vibrational bands is noticeable except for the red system of $\mathrm{UH}^{+}$. Although it has to be taken with caution, the widths of the bands were fitted by a Lorentzian function to extract excited state lifetimes using the uncertainty principle, and the validity of this assumption will be discussed in section 4.a.

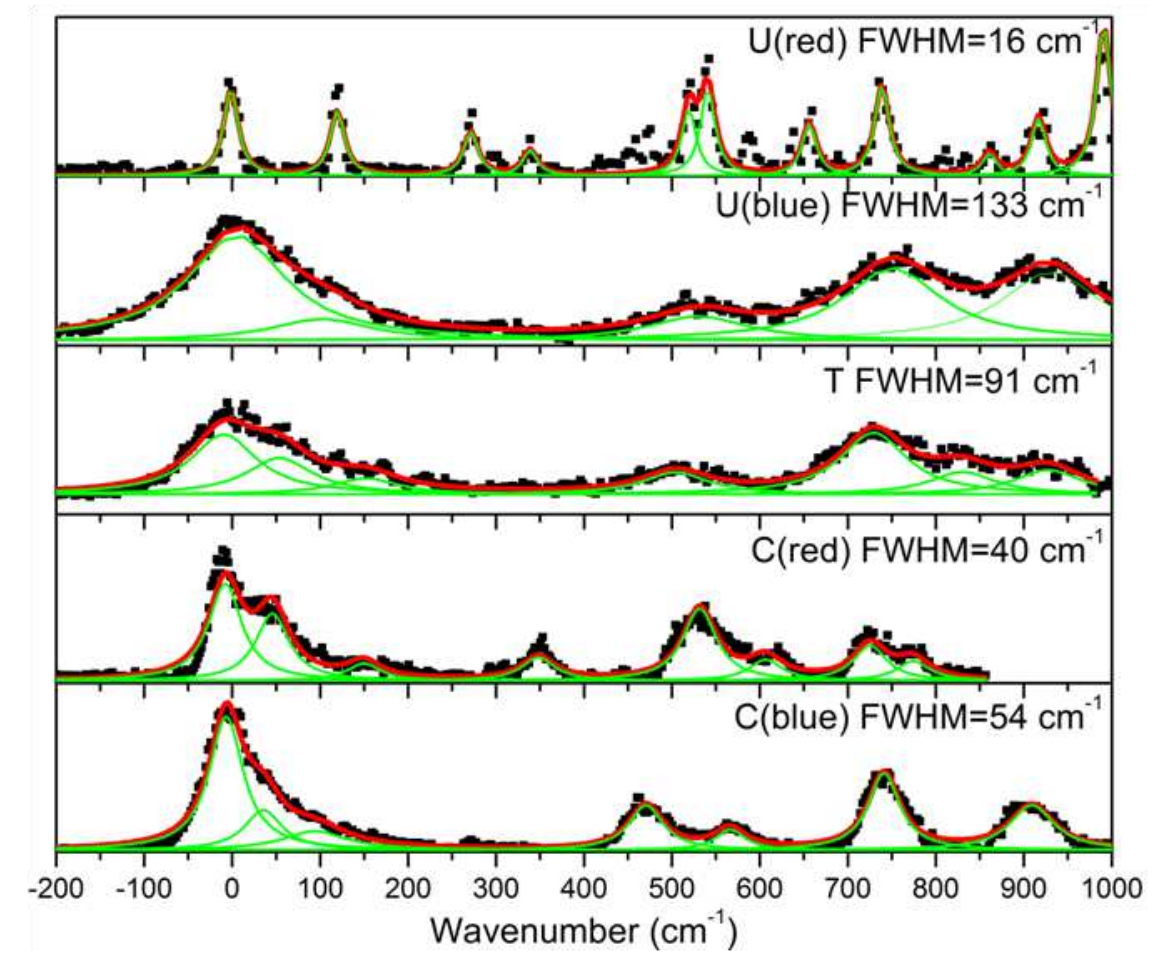

Figure 3. Low energy part of the spectra of the protonated pyrimidine bases. The vibrational bands (fitted with Lorentzian peaks) are very broad, except for the lowest electronic transition of protonated uracil red band system which was fitted to a Voigt profile with a Gaussian width of $12 \mathrm{~cm}^{-1}$ that corresponds to the laser bandwidth and rotational contour. FWHM is full width at half maximum of the Lorentzian functions used to simulate the bands of each tautomer.

An enlarged view of the spectra near the band origin for the protonated purine bases is depicted in Fig. 4. Protonated guanine shows a well resolved spectrum with narrow bands (FWHM=12 $\pm 2 \mathrm{~cm}^{-1}$ ). Protonated adenine presents two band systems composed of a very broad absorption band on the red part of the spectrum and a group of broad peaks starting at $1000 \mathrm{~cm}^{-1}$ to the blue of the origin of the red band. It must be noticed that for the very broad part of the spectrum in the low energy region, the 
intensity of the two fragments $\left(\mathrm{m} / \mathrm{z} 94\left(-\mathrm{H}_{2} \mathrm{NCN}\right)\right.$ and $\left.119\left(-\mathrm{NH}_{3}\right)\right)$ is the same whereas for the blue band system the $-\mathrm{NH}_{3}$ fragment is more intense than the $-\mathrm{H}_{2} \mathrm{NCN}$ fragment, indicating the existence of two electronic states or isomers. The excited state lifetimes for $\mathrm{GH}^{+}$and the blue band system of $\mathrm{AH}^{+}$ obtained from the fit of the bandwidth are also reported in Table 1.
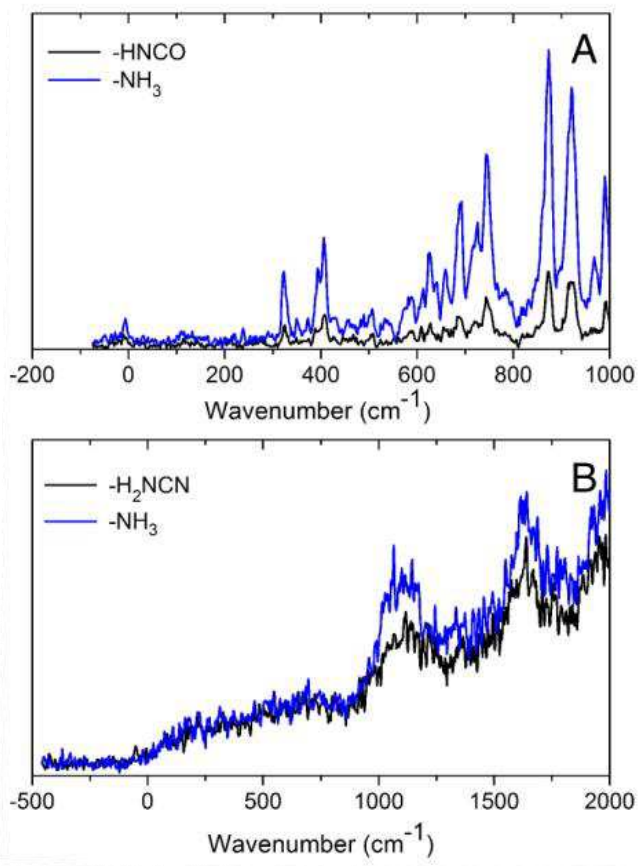

Figure 4. Low energy part of the spectra of the protonated purine bases. A ) Protonated guanine in the energy region between 200 and $1000 \mathrm{~cm}^{-1}$ around the $0-0$ transition, which is very weak. The width of the first vibrational bands is $12 \mathrm{~cm}^{-1}$ and corresponds to the convolution of a cold rotational contour with the laser bandwidth. B) Protonated adenine in the energy region between -500 and $2000 \mathrm{~cm}^{-1}$ around the photofragmentation onset. In the lower energy part $\left(0-800 \mathrm{~cm}^{-1}\right)$ the two fragmentation channels have the same intensity whereas on the bands at 1100 and $1600 \mathrm{~cm}^{-1}$ the $\mathrm{m} / \mathrm{z} 119$ fragment ( $\mathrm{NH}_{3}$ loss) is more intense than the $\mathrm{m} / \mathrm{z} 94$ fragment $\left(\mathrm{H}_{2} \mathrm{NCN}\right.$ loss). This most probably reflects the presence of two tautomers. 


\section{Analysis and Discussion}

\section{4.a. Determination of the excited state Lifetimes}

The excited state lifetimes have been estimated from the widths of the bands fitted by Lorentizan functions as can be seen in Fig. 3, except for $\mathrm{GH}^{+}$and $\mathrm{UH}^{+}(\mathrm{red})$ that were fitted to Voigt profiles to account for the rotational contour and the laser Gaussian bandwidth $\left(12 \mathrm{~cm}^{-1}\right)$ convolution. The fitting of the other spectra gives the same Lorentzian bandwidth independently of fitting to Voigt or Lorentzian profiles.

The relationship between the Lorentzian bandwidth and the excited state lifetime is given by the uncertainty principle which can be written as:

$$
F W H M\left(\mathrm{~cm}^{-1}\right)=(2 \pi \mathrm{c} \tau)^{-1}=5.3 \times 10^{-12} / \tau(s)
$$

The Full Width at Half Maximum (FWHM) of the peak is given in $\mathrm{cm}^{-1}$ and the lifetime $\tau$ in seconds. This procedure is valid if it can be assumed that the broadening is only due to the excited state lifetime and not to spectral congestion (e.g. rotational contour or low frequency active modes).

For the red band system of $\mathrm{UH}^{+}$(Fig. 3) as well as for $\mathrm{GH}^{+}$(Fig. 4) that present well resolved narrow vibrational structure, no low frequency progressions (lower than $100 \mathrm{~cm}^{-1}$ ) are observed. Therefore, there are no reasons to expect low vibrational frequency progressions blended into a spectral background of the other bases for which very broad bands are observed.

The ground state vibrational frequencies were calculated for all the protonated bases and the lowest frequencies corresponding to out-of-plane modes are in the order of $200 \mathrm{~cm}^{-1}$. At the low temperature of the experiment, the vibrational modes of the electronic ground state are not excited. Thus, the band broadening is not expected to be due to hot band sequences. Under the assumption that the excited state frequencies are in the same range as the ground state frequencies $\left(200 \mathrm{~cm}^{-1}\right)$, any vibrational progression in low frequency modes would have been easily separated in the absence of 
lifetime broadening, as in the case of the red system of $\mathrm{UH}^{+}$or of $\mathrm{GH}^{+}$. It is thus reasonable to assume that the bandwidths are intrinsic and that lifetimes can be deduced.

The estimated lifetimes are listed in Table 1 and are found between $30 \mathrm{fs}$ and $100 \mathrm{fs}$ ( $\pm 50 \mathrm{fs}$ ) for most of the species except for $\mathrm{GH}^{+}$and the red band system of $\mathrm{UH}^{+}$that shows only a small broadening as compared to $\mathrm{GH}^{+}$, and should have a lifetime longer than a few hundreds of femtoseconds.

Table 1. Bandwidth and excited state lifetimes of the different electronic systems of the five protonated bases

\begin{tabular}{|l|c|c|}
\hline Protonated base & Measured & Estimated lifetimes \\
& FWHM $\left(\mathrm{cm}^{-1}\right)$ & \\
\hline Uracil red system & \\
\hline Uracil blue system & $16 \pm 5$ & $40 \pm 20$ \\
\hline Thymine & $91 \pm 20$ & $58 \pm 20$ \\
\hline Cytosine red system & $40 \pm 10$ & $133 \pm 20$ \\
\hline Cytosine blue system & $54 \pm 10$ & $98 \pm 20$ \\
\hline Adenine blue system $^{\text {a }}$ & $177 \pm 20$ & $30 \pm 20$ \\
\hline Guanine & & $>5000$ \\
\hline
\end{tabular}

\footnotetext{
${ }^{a}$ The width of the bands in protonated Guanine $\left(<1 \mathrm{~cm}^{-1}\right)$ and in protonated Uracil red system $\left(16 \pm 5 \mathrm{~cm}^{-1}\right)$ corresponds to the Lorentzian bandwidth of a Voigt profile, given a Gaussian function (FWHM=12 $\mathrm{cm}^{-1}$ ) that represents the convolution of the rotational contour and the laser bandwidth. For the protonated Uracil red system, the bands are only slightly larger than the guanine bands so that the lifetime may be longer than $330 \mathrm{fs}$.
}

We do not observe a large change of the broadening of the bands with the excess energy in contrast with other systems such as neutral adenine, for which a few bands are well resolved at low energy and a continuous absorption is observed at higher energy indicating a shorter lifetime. ${ }^{26,27}$ In 
protonated bases, the non-radiative processes leading to the fast decays are present on the $0-0$ transition and do not change drastically at least for the first $1000 \mathrm{~cm}^{-1}$ above the origin. At higher energy the spectra become structure-less but this is most probably due to spectral congestion.

It is worth noting that the short excited state lifetime determined here corresponds to the $\pi \pi^{*}$ excited state lifetime. These lifetimes do not give direct information on the rate of the dissociation process that leads to the photofragments detected. The photofragmentation takes place most likely in the electronic ground state, following fast IC as in the case of neutral DNA bases, which is expected to be the main deactivation pathway associated with the $\pi \pi^{*}$ excited state lifetime.

In the gas phase isolated system, IC produces highly vibrationally excited ions for which one possibility for energy dissipation is the unimolecular dissociation. However, in bulk systems, the major energy dissipation mechanism is vibrational relaxation through energy transfer to the solvent and the environment or even IVR to the whole DNA molecule, insuring the stability of the molecule. ${ }^{1-4}$

\section{4.b Tautomers Assignment}

Generally for neutral and protonated aromatic molecules, geometry optimization of the first excited state at the $A D C(2)$ level leads to adiabatic transition energies in very good agreement with experimental values, the mean error being around $\pm 0.2 \mathrm{eV} .{ }^{15,28-32}$ In the present study, it was possible to optimize only the excited state of the most stable isomer of $\mathrm{CH}^{+}$(the enol/1H-2H tautomer). The calculated adiabatic transition is $4.62 \mathrm{eV}$, in very good agreement with the experimental value of the origin of the blue system $(4.63 \mathrm{eV})$, being within the usual $0.2 \mathrm{eV}$ (even much smaller in this case). For this case, the assignment of the spectrum seems quite certain (see below A-Cytosine).

As a general trend, the excited state optimization process for aromatic molecules (neutral or protonated) leads to a stabilization of c.a. $0.5 \mathrm{eV}$ as compared to the vertical excitation energy $\left(\mathrm{E}_{\mathrm{vert}}\right) .^{15,28-}$

\footnotetext{
${ }^{32}$ In the case of the enol/1H-2H tautomer of $\mathrm{CH}^{+}, \mathrm{E}_{\text {vert }}$ is $5.15 \mathrm{eV}$ and the stabilization is expected to lead
} 
to an adiabatic transition energy $E_{a d}=E_{v e r t}-0.5 \mathrm{eV}=4.65 \mathrm{eV}$ in very good agreement with the experimental value $(4.63 \mathrm{eV})$ and the calculated adiabatic transition energy $(4.62 \mathrm{eV})$. Therefore, the empirical rule:

$$
E_{\text {exp }}=E_{\text {vert }}(0.5 \pm 0.3 \mathrm{eV}) \quad \text { (Eq. 2) }
$$

that correlates the experimental excitation energy $\left(\mathrm{E}_{\mathrm{exp}}\right)$ with the calculated vertical excitation energy $\left(E_{\text {vert }}\right)$, was used to assign all the observed electronic spectra, which can all be assigned to the most stable ground state tautomers of the protonated bases.

The calculated vertical excitation energies together with the experimental transition energies and the difference $\delta=\left(E_{\text {vert }}-0.5\right)-E_{\text {exp }}$ for the main tautomers are summarized in Table 2. 
Table 2. Assignment of the electronic transitions to different tautomers of the protonated DNA/RNA bases. The crossed enol-keto protonated thymine tautomer might be populated in the ground state due to its low energy, but is not observed. For the ground state $\left(S_{0}\right)$ the energies are relative to the energy of the most stable tautomer. All units are in $\mathrm{eV}$.

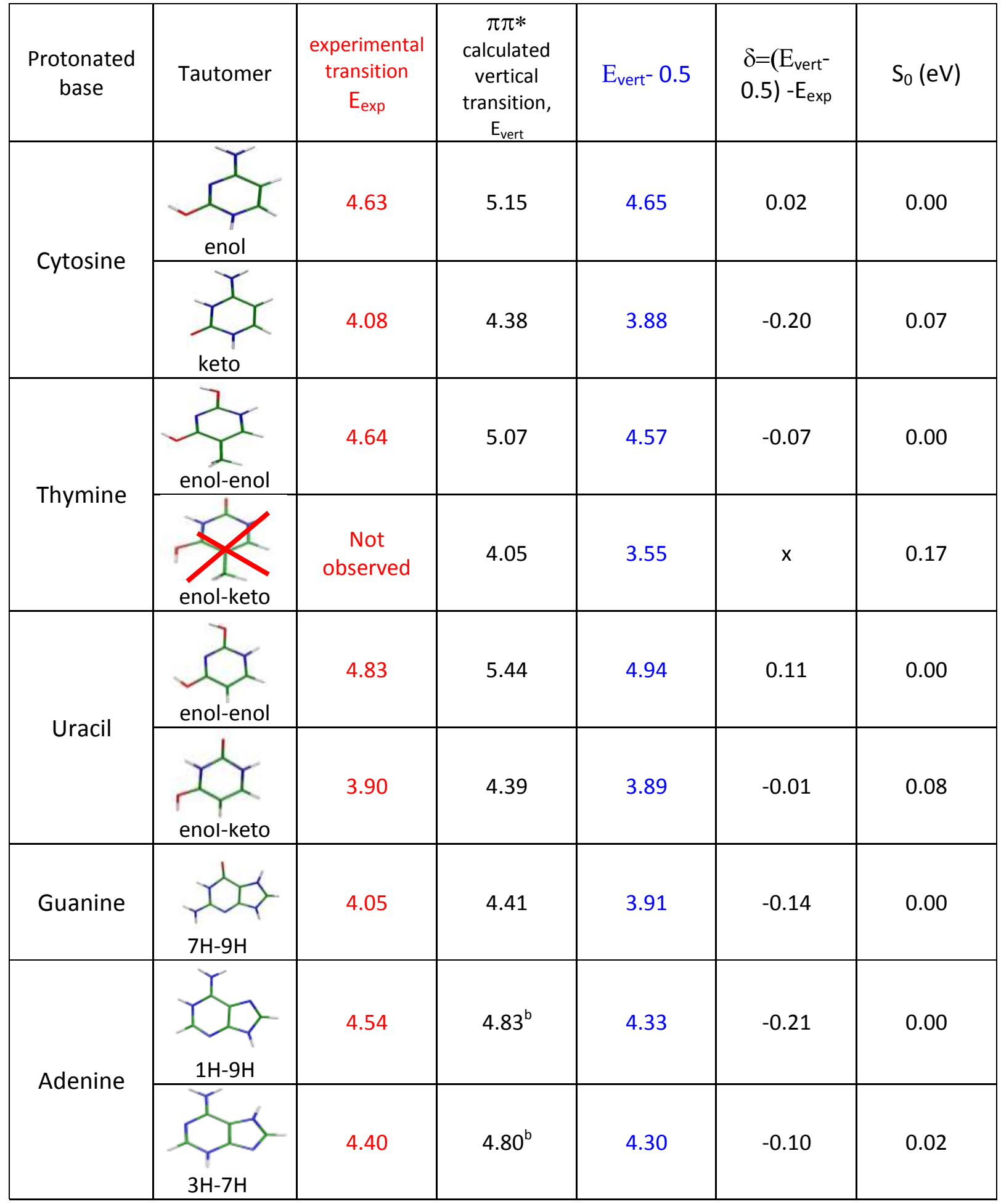

${ }^{b}$ Taken from Ref. (12) 


\section{A- Cytosine ${ }^{+}$}

For $\mathrm{CH}^{+}$we clearly detect the 2 lowest energy isomers. Both have very distinct band origins and the vertical transition energy calculation of higher energy states excludes the assignment of the two band systems to two excited states of the same tautomer. The most stable tautomer has an enol/1H-2H (see figure 1 for atom numbering) form as already determined by IR-MPD spectroscopy.,

For this tautomer the excited state optimization was possible and the calculated adiabatic transition of $4.62 \mathrm{eV}$ is in very good agreement with the experimental value of the blue band system (4.63 eV). The blue band system (Fig. 1) is thus assigned to enol/1H-2H tautomer. For this tautomer, the ground and excited state frequencies have been calculated and the spectrum can be satisfactorily simulated as shown in Fig. 5. The lowest out-of plane frequency is calculated at $95 \mathrm{~cm}^{-1}$ in the excited state and is only very weakly active with one quantum ( $v_{1}$ not visible in Fig. 5 ) and more active with 2 quanta ( $2 v_{1}$ visible in Fig. 5). The agreement between the simulated spectrum and the experimental one is very good, showing active modes which are mainly in-plane modes. Only the mode observed at +950 $\mathrm{cm}^{-1}$ is missing in the simulation.

For the second isomer keto/1H-3H, also characterized by IR-MPD spectroscopy, ${ }^{5,7}$ the $\pi \pi^{*}$ optimization leads to a crossing with a $n \pi^{*}$ state through the $\mathrm{NH}_{2}$ rotation. Thus, the excited state optimization was not successful and the adiabatic energy of the $\pi \pi^{*}$ cannot be obtained. However, taking into account the ground state energy and the calculated vertical energy, the assignment of the electronic spectrum of the red band system to the keto/1H-3H tautomer can be quite ascertained. Both tautomers have short excited state lifetimes (Table 1). 


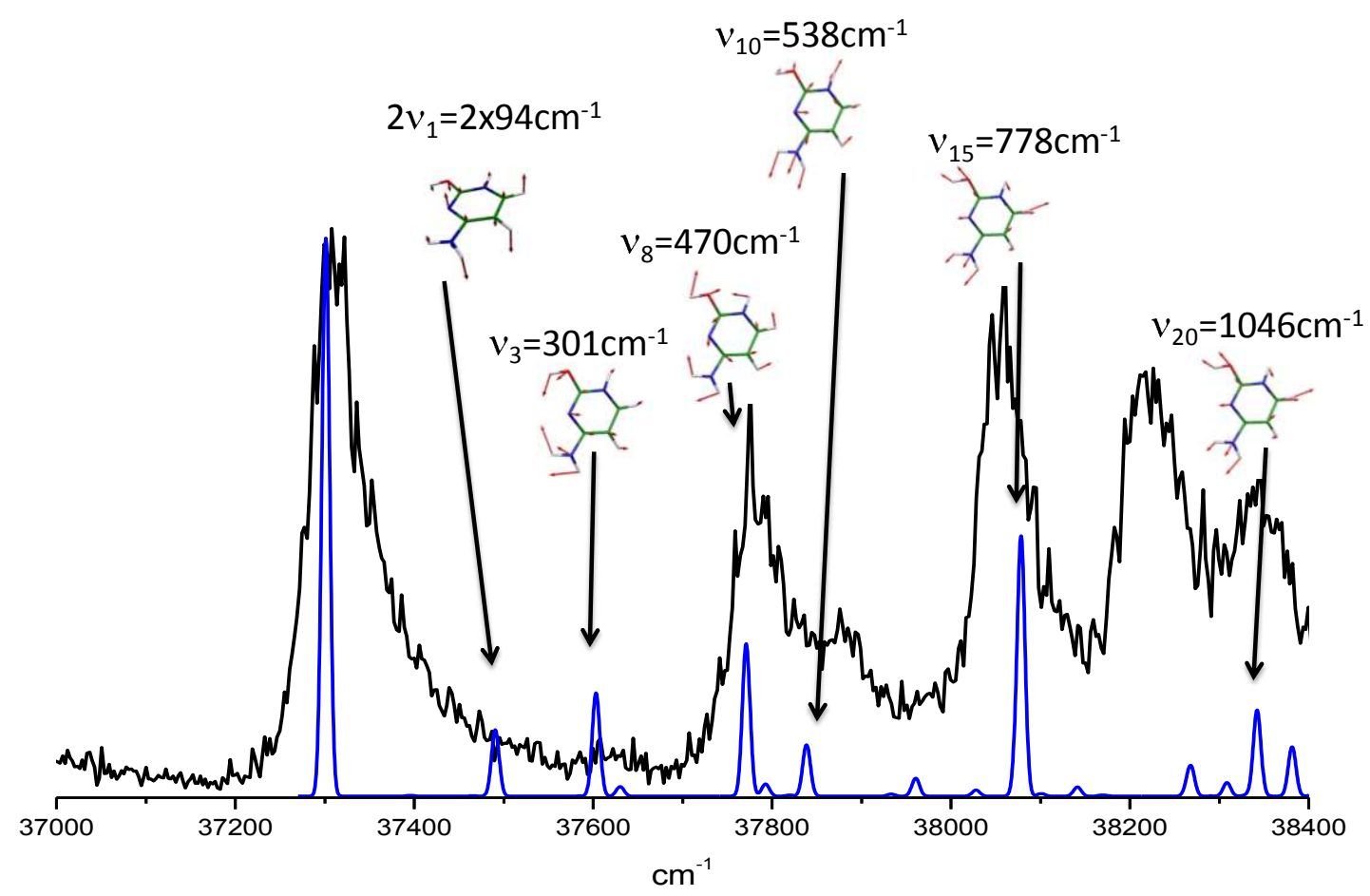

Figure 5. In black the enol/1H-2H tautomer of $\mathrm{Cytosine}^{+}$experimental spectrum. In blue the calculated spectrum. Above each transition the vibrational mode involved for each calculated band.

\section{B- ThymineH ${ }^{+}$}

For $\mathrm{TH}^{+}$, the most stable tautomer has an enol-enol/2H-4H structure, and the transition energy calculated with the empirical rule (Eq. 2) agrees with the observed electronic transition energy. For the second isomer, the ground state energy is calculated $0.17 \mathrm{eV}$ higher than the enol-enol/2H-4H form, at the MP2 level of theory, while the energy difference calculated by Salpin et al. ${ }^{5}$ at the B3LYP level was $0.1 \mathrm{eV}$. The electronic transition can be predicted to lie at lower energy (around 4.05-0.5=3.55 eV/ 350 $\mathrm{nm})$, but this isomer was not detected in our experiment. So we assign the $\mathrm{TH}^{+}$tautomer observed in our experiment to enol-enol/2H-4H tautomer. Similarly to $\mathrm{CH}^{+}$, the excited state lifetime of the observed tautomer is very (Table 1 ). 


\section{C- UracilH}

The spectrum of $\mathrm{UH}^{+}$shows two bands systems, which can be assigned to the two lowest energy ground state isomers. The lowest isomer has again an enol-enol $/ 2 \mathrm{H}-4 \mathrm{H}$ structure as reported previously

5,6 and the first electronic transition is estimated to be at $4.94 \mathrm{eV}$ from the empirical rule (Eq. 2). We can then associate the blue band system starting at $4.83 \mathrm{eV}(257 \mathrm{~nm})$ to the first electronic transition of this enol-enol/2H-4H tautomer. The other tautomer (enol-keto/3H-4H) has a ground state energy calculated at $0.08 \mathrm{eV}$ at the MP2 level and $0.05 \mathrm{eV}$ at the B3LYP level ${ }^{5}$ and its electronic transition should be observed at lower energy than the enol-enol/2H-4H transition energy, according to the empirical rule that leads to a calculated transition energy around 4.39-0.5=3.89 eV (318 nm). Indeed, the first band of the red system is observed at $314.8 \mathrm{~nm}$. Therefore, the red band system is assigned to this second tautomer, enol-keto/3H-4H. In this case, as shown in Table 1 , both isomers have very different excited state lifetime (Table 1), the enol-keto/3H-4H (red system) being longer lived than the enol-enol/2H-4H (blue system).

\section{D- GuanineH ${ }^{+}$}

In the case of $\mathrm{GH}^{+}$, the $7 \mathrm{H}-9 \mathrm{H}$ tautomer has been shown to be more stable than the other ones by at least $23 \mathrm{~kJ} / \mathrm{mol}(0.24 \mathrm{eV}) .{ }^{33}$ Once more, the observed spectrum can be assigned to this tautomer using the empirical rule (Eq. 2). The spectrum presents well resolved vibrational bands that can be followed for more than $1000 \mathrm{~cm}^{-1}$ without any sign of spectral broadening, indicating the absence of very fast non-radiative decay.

\section{E- AdenineH ${ }^{+}$}

The experimental spectrum $\mathrm{AH}^{+}$is composed of two systems very close in energy. One extremely broad system, which looks like a continuum, is starting at $282 \mathrm{~nm}\left(4.40 \mathrm{eV}=35460 \mathrm{~cm}^{-1}\right)$ and another 
system starting at higher energy $(+0.15 \mathrm{eV})$ is composed of a broad vibrational progression with the first band at $273 \mathrm{~nm}\left(4.54 \mathrm{eV}=36630 \mathrm{~cm}^{-1}\right)$. In fact, three ground state tautomers have been calculated to lie within less than $0.1 \mathrm{eV}$ and their vertical electronic excitation energies are also within $0.1 \mathrm{eV},{ }^{12}$ thus the empirical rule (Eq. 2) cannot be used unambiguously. The state-of-the-art ab-initio calculations have already been performed by Marian et al., ${ }^{12}$ thus we did not perform any calculation for this system but just compared with previous calculations. In the ground state the $1 \mathrm{H}-9 \mathrm{H}$ tautomer is the most stable one, followed by the $3 \mathrm{H}-7 \mathrm{H}$ and the $3 \mathrm{H}-9 \mathrm{H}$ tautomers at $0.02 \mathrm{eV}$ and $0.08 \mathrm{eV}$ above the energy of the $1 \mathrm{H}-9 \mathrm{H}$ tautomer, respectively.

The $3 \mathrm{H}-9 \mathrm{H}$ tautomer can probably be ruled out since its absorption lies in the $320 \mathrm{~nm}$ region ${ }^{13}$ and, taking into account the ion trap temperature and the ground state energies, the population of this species is expected to be very low.

The other two tautomers $(1 \mathrm{H}-9 \mathrm{H}$ and $3 \mathrm{H}-7 \mathrm{H})$ have very similar vertical electronic transition energies at $4.83 \mathrm{eV}$ and $4.80 \mathrm{eV}$, respectively. The energy gap between the two first $\pi \pi^{*}$ states of each of these two tautomers are around $0.2-0.3 \mathrm{eV}$ larger than the observed energy gap between the two experimental electronic transitions. Thus one can probably assign the two systems to different tautomers.

In the low energy system the intensity of the $m / z=94$ and $m / z=119$ fragments arising from $\mathrm{H}_{2} \mathrm{NCN}$ and $\mathrm{NH}_{3}$ loss are the same whereas on the higher energy band system the $\mathrm{m} / \mathrm{z} 119$ fragment becomes more intense than $\mathrm{m} / \mathrm{z} 94$. Very likely, this difference arises from the different structures of the tautomers responsible for each absorption band and this argument can be used to assign the spectra.

The $\mathrm{H}_{2} \mathrm{NCN}$ fragment can be produced by direct fragmentation of the $3 \mathrm{H}-7 \mathrm{H}$ tautomer while in the case of the $1 \mathrm{H}-9 \mathrm{H}$ tautomer the formation of this fragment would require a subsequent $\mathrm{H}$ atom loss or a previous rearrangement of the structure. In any case, the rate of production of the $\mathrm{H}_{2} \mathrm{NCN}$ fragment from $1 \mathrm{H}-9 \mathrm{H}$ tautomer is expected to be lower that from the $3 \mathrm{H}-7 \mathrm{H}$ tautomer and then its branching ratio 
should be also lower. Then, we can assume that the higher energy band system is due to the $1 \mathrm{H}-9 \mathrm{H}$ tautomer, while the lower energy system is due to the $3 \mathrm{H}-7 \mathrm{H}$ tautomer. Nevertheless, an unambiguous assignment would require additional work such as IR-UV spectroscopy. Both tautomers have very short excited state lifetime (Table 1).

\section{4.c. Lifetimes of protonated tautomers}

The keto/1H-3H and the enol/1H-2H tautomers of $\mathrm{CH}^{+}$and the $1 \mathrm{H}-9 \mathrm{H}$ tautomer of $\mathrm{AH}^{+}$can be obtained by proton transfer (PT) reaction in the canonical WC structures (Fig. 1). We observed short excited state lifetimes for these tautomers. On the other hand, the $7 \mathrm{H}-9 \mathrm{H}$ tautomer of $\mathrm{GH}^{+}$(long excited state lifetime) and the enol-enol/2H-4H tautomer of $\mathrm{TH}^{+}$(short excited state lifetime) cannot be produced by PT reaction within the CG and TA WC base pairs, respectively. Therefore, the electronic properties of the canonical $\mathrm{CH}^{+}$and $\mathrm{AH}^{+}$, which are biological significant, are expected to be relevant for the DNA photostability. In line with the results obtained for neutral isolated DNA/RNA bases, for which the biologically most relevant forms exhibit the shortest excited state lifetimes, ${ }^{1-3}$ the same rule seems to hold for the protonated bases. Canonical $\mathrm{CH}^{+}$and $\mathrm{AH}^{+}$have short excited state lifetime, while the excited state lifetime of the non-canonical $\mathrm{GH}^{+}$tautomer is longer by at least three orders of magnitude.

The excited states of the WC bases pairs have also very short lifetime, a property that is related to photostability of DNA. ${ }^{34,35}$ The processes at play have been the subject of many investigations ${ }^{1-3,11,34-}$

${ }^{38}$ but it is not so easy to get a unified mechanism since there are many possible deactivation pathways, which have not all been explored.

The similarity between the electronic properties e.g: excitation energy and very short excited state lifetimes for canonical tautomers of the neutral and protonated DNA bases, reported here, suggests that the latter could also play an important role in the photostability mechanisms of DNA. Thus 
this paper provides a complete set of data that can be used as experimental benchmark for theoretical excited state dynamics calculations.

\section{Conclusions}

We have presented here a complete set of experimental data concerning the excited states of the protonated DNA/RNA bases. When the comparison with neutral homologue can be done the electronic transition energies do not change drastically between neutral and protonated species. In contrast, the excited state lifetime of the protonated species seems to be very short except for guanine and one uracil tautomer. This challenges theoretical calculations and these results are benchmark for testing ab-initio methods, in particular to identify the non-radiative processes. However standard excited state calculations constitute a good tool to allow identification of tautomers. ${ }^{\ddagger}$ In this paper, since the excited state lifetimes are extracted from vibrational broadening, the values can neither describe possible non-exponential decays nor variation of these lifetimes with the excess energy. Thus femtosecond pump-probe experiment would be highly desirable.

\section{Acknowledgements}

This works was supported by ECOS-MinCyT cooperation program (A11E02) the ANR Research Grant (ANR2010BLANC040501), FONCYT, CONICET and SeCYT-UNC. We acknowledge the use of the computing facility cluster GMPCS of the LUMAT federation (FR LUMAT 2764).

\footnotetext{
${ }^{\ddagger}$ We also confirmed recently the identification of different tautomers of protonated uracil with a new UV-UV hole-burning spectroscopy. ${ }^{39}$
} 


\section{References and Notes}

1. K. Kleinermanns, D. Nachtigallová and M. S. de Vries, Int. Rev. Phys. Chem.,2013, 32, 308-342.

2. C. E. Crespo-Hernández, B. Cohen, P. M. Hare and B. Kohler, Chem. Rev.,2004, 104, 1977-2019.

3. H. Saigusa, J. Photoch. Photob. C: Photoch. Rev.,2006, 7, 197-210.

4. D. Tuna, A. L. Sobolewski and W. Domcke, J. Phys. Chem. A, 2014, 118, 122-127.

5. J. Y. Salpin, S. Guillaumont, J. Tortajada, L. MacAleese, J. Lemaire and P. Maitre, Chem. Phys. Chem.,2007, 8, 2235-44.

6. J. M. Bakker, R. K. Sinha, T. Besson, M. Brugnara, P. Tosi, J. Y. Salpin and P. Maitre, J. Phys. Chem. A.,2008, 112, 12393-12400.

7. J. M. Bakker, J. Y. Salpin and P. Maitre, Int. J. Mass Spect., 2009, 283, 214-221.

8. L. D. Williams and B. Ramsay Shaw, Proc. Natl. Acad. Sci. USA, 1987, 84, 1779-1783.

9. N. Russo, M. Toscano, A. Grand and F. Jolibois, J. Comp. Chem., 1998, 19, 989-1000.

10. S. Y. Han, S. H. Lee, J. Chung and H. B. Oh, J. Chem. Phys., 2007, 127, 245102.

11. A. L. Sobolewski and W. Domcke, Phys. Chem. Chem. Phys., 2004, 6, 2763-2771.

12. C. Marian, D. Nolting and R. Weinkauf, Phys. Chem. Chem. Phys., 2005, 7, 3306-3316.

13. N. R. Cheong, S. H. Nam, H. S. Park, S. Ryu, J. K. Song, S. M. Park, M. Pérot, B. Lucas, M. Barat, J. A. Fayeton and C. Jouvet, Phys. Chem. Chem. Phys., 2011, 13, 291-295.

14. S. Øvad Pedersen, K. Støchkel, C. Skinnerup Byskov, L. Munksgaard Baggesen and S. Brøndsted Nielsen, Phys. Chem. Chem. Phys., 2013, 15, 19748-19752.

15. I. Alata, J. Bert, M. Broquier, C. Dedonder, G. Feraud, G. Grégoire, S. Soorkia and Jouvet, C., J. Phys. Chem. A, 2013, 117, 4420-4427.

16. X. B. Wang and L. S. Wang, Rev. Sci. Instrum., 2008, 79, 073108.

17. M. Z. Kamrath, R. A. Relph, T. L. Guasco, C. M. Leavitt, M. A. Johnson, Int. J. Mass Spectrom., 2010, 300, 91-98. 
18. C. M. Choi, H. J. Kim, J. H. Lee, W. J. Shin, T. O. Yoon, N. J. Kim and J. Heo, J. Phys. Chem. A, 2009, 113, 8343-8350.

19. J. U. Andersen, H. Cederquist, J. S. Forster, B. A. Huber, P. Hvelplund, J. Jensen, B. Liu, B. Manil, L. Maunoury, S. Brøndsted Nielsen, U. V. Pedersen, J. Rangama, H. T. Schmidt, S. Tomita and H. Zettergren, Phys. Chem. Chem. Phys., 2004, 6, 2676-2681.

20. R. Ahlrichs, M. Bär, M. Häser, H. Horn and C. Kölmel, Chem. Phys. Lett., 1989, 162, 165-169.

21. C. Hattig, J. Chem. Phys., 2003, 118, 7751-7761.

22. J. Schirmer, Phys. Rev. A, 1982, 26, 2395 -2416.

23. D. E. Woon, T. H. Dunning, J. Chem. Phys., 1993, 98, 1358-1371.

24. We use the notation $1 \mathrm{H}-2 \mathrm{H}$ to indicate the hydrogen and proton positions on nitrogen numbered 1 and on the oxygen linked to carbon 2 (see Fig. 1 for atom numbering).

25. C. M. Western, (n.d.), PGOPHER, a Program for Simulating Rotational Structure. V 7.0.101. PGOPHER, a Program for Simulating Rotational StructureWestern, University of Bristol, http://pgopher.chm.bris.ac.uk.

26. N. J. Kim, G. Jeong, Y. S. Kim, J. Sung, S. K. Kim and Y. D. Park, J. Chem. Phys., 2000, 113, 10051-10055.

27. M. Miyazaki, H. Kang, C. M. Choi, N. S. Han, J. K. Song, N. J. Kim and M. Fujii, J. Chem. Phys., 2013, 139, 124311.

28. I. Alata, D. Dedonder, M. Broquier, E. Marceca and C. Jouvet, J. Am. Chem. Soc., 2010, 132, 1748317489.

29. G. A. Pino, A. N. Oldani, E. Marceca, M. Fujii, S.-I. Ishiuchi, M. Miyazaki,M. Broquier, C. Dedonder and C. Jouvet, J. Chem. Phys., 2010, 133, 124313.

30. G. Gregoire, C. Jouvet, C. Dedonder and A. L. Sobolewski, J. Am. Chem. Soc., 2007, 129, 6223-6231.

31. G. A. Pino, I. Alata, C. Dedonder, C. Jouvet, K. Sakota and H. Sekiya, Phys. Chem. Chem. Phys., 2011, 13, 6325-6331. 
32. M. C. Capello, M. Broquier, C. Dedonder-Lardeux, C. Jouvet and G. A. Pino, J. Chem. Phys., 2013, 138, 054304.

33. A. K. Chandra, M. T. Nguyen and T. Uchimaru, J. Phys. Chem. A, 1999, 103, 8853-8860.

34. A. Abo-Riziq, L. Grace, E. Nir, M. Kabelac, P. Hobza and M. S. De Vires, Proc. Natl. Acad. Sci. USA, $2005,102,20-23$.

35. T. Schultz, E. Samoylova, W. Radloff, I. V. Hertel, A. L. Sobolewski and W. Domcke, Science, 2004, 306, 1765-1768.

36. E. Nir, K. Kleinermanns and M. S. de Vries, Nature, 2000, 408, 949-951.

37. C. Canuel, M. Mons, F. Piuzzi, B. Tardivel, I. Dimicoli and M. Elhanine, J. Chem. Phys., 2005, 122, 074316.

38. D. Nachtigallová, H. Lischka, J. J. Szymczak, M. Barbatti, P. Hobza, Z. Gengeliczki, G. Pino, M. P. Callahan and M. S. de Vries, Phys. Chem. Chem. Phys., 2010, 12, 4924-4933.

39. G. Féraud, C. Dedonder-Lardeux, C. Jouvet, Y. Inokuchi, T. Haino, R. Sekiya and T. Ebata, J. Phys.

Chem. Lett., 2014, 5, 1236-1240 


\section{TABLE OF CONTENTS}

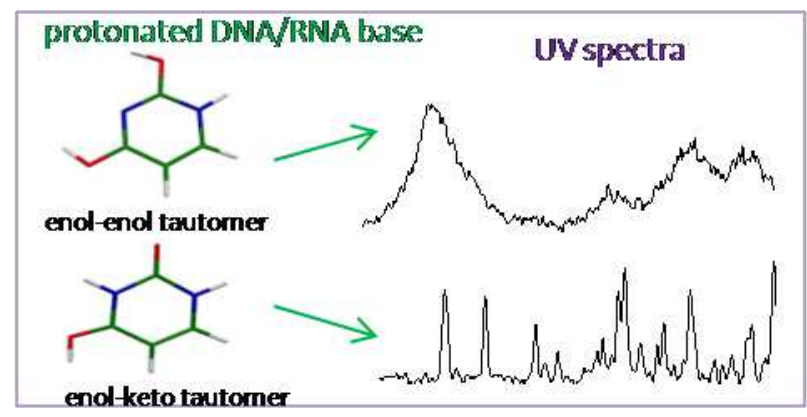

The excited state lifetime of protonated DNA/RNA bases is strongly dependent on the tautomeric form. 